\title{
Smart Market Yard System
}

\author{
Sarvesh Khandelwal ${ }^{1}$, Pawan Kumar ${ }^{2}$, Rushabh Khimawat ${ }^{3}$, Prof. Namrata N. Wasatkar ${ }^{4}$ \\ Comp Dept, VIIT, Vishwakarma Institute of Information Technology, Pune, India ${ }^{1,2,3}$ \\ Guide, Comp Dept, VIIT, Vishwakarma Institute of Information Technology, Pune, India ${ }^{4}$
}

\begin{abstract}
Agriculture is the backbone of Indian economy. It is one of the major sectors of Indian economy known as primary market. Agricultural Marketing study is the study of all the activities, agencies and policies included in the procurement of farm inputs by the farmers and the procedure of movement of agricultural products from the farmers to the consumers.. Traditional marketing system which was highly regulated opened up owing to changing system and emerging agribusiness. Increase in marketable surplus of agricultural commodities, urbanization and changes in consumption pattern have also contributed to the changing systems. Accordingly, both the Central and State governments initiated policy reforms in marketing to address to the drawbacks in the existing marketing to meet the challenges and requirements of emerging business opportunities. This led to the evolution of new initiatives in marketing of agricultural commodities. Commodities produced have to support a series of operations such as threshing, storage, winnowing, transportation, harvesting, bagging processing and interchange before they reach the market, and as visible from many studies across the country, there are considerable losses in commodities output at all these stages. In this system We send the commodity to the buyer agent. In this paper we develop the android application in that farmer send the commodity detail to agent, agent give it to gate person then using application gate person give detail of farmer, agent commodity to shopkeeper.
\end{abstract}

Keywords: Commodities, Data Mining, Agricultural Commodities, Support Vector Machine (SVM), and Logistic Regression (LR)

\section{INTRODUCTION}

Growing demand for high-value food commodities is new opportunities for farmers, especially for smallholders to diversify towards commodities that have strong potential for higher returns to land, labor and capital. It is to satisfy the customer at optimum cost. Due to globalization, liberalization and advancement Market liberalization and globalization are causing a transformation in agriculture and agree-food markets in India. So we make Android application and in that Farmer send her commodity with Agent. Then Agent deliver his commodity to that gate person. Then gate person check her details. And the details is Farmer Name, Product, Vehicle name, and then Agent name. This type of information they will get. Then Agent deliver his commodity to that supplier. And Supplier at the end Generate the report. Admin check the Agent activity. As well as admin see the Agent route. And to detect and improve the fraudulent activities. The main objectives of study were to identify the arrival pattern of certain produce and their values in to the market yard; to find out the perceptions of the farmers on overall marketing infrastructure support; to determine the problems faced by farmers while using this infrastructure.

\section{LITERATURE SURVEY}

1. H. Zhang, Z. X. Cao, M. Li, Y. Z. Li, and C. Peng, "Novel naïve Bayes classification models for predicting the carcinogenicity of chemicals," Food Chem. Toxicol., vol. 97, pp. 141-149, 2016.[3]

Carcinogenicity refers to a highly toxic end point of certain chemicals, and has become an important issue in the drug development process. In this study, three novel ensemble classification models, namely Ensemble SVM, Ensemble RF, and Ensemble XGBoost, were developed to predict carcinogenicity of chemicals using seven types of molecular fingerprints and three machine learning methods based on a dataset containing 1003 diverse compounds with rat carcinogenicity. Among these three models, Ensemble XGBoost is found to be the best, giving an average accuracy of $70.1 \pm 2.9 \%$, sensitivity of $67.0 \pm 5.0 \%$, and specificity of $73.1 \pm 4.4 \%$ in five-fold cross-validation and an accuracy of $70.0 \%$, sensitivity of $65.2 \%$, and specificity of $76.5 \%$ in external validation. In comparison with some recent methods, the ensemble models outperform some machine learning-based approaches and yield equal accuracy and higher specificity but lower sensitivity than rule-based expert systems. It is also found that the ensemble models could be further improved if more data were available. As an application, the ensemble models are employed to discover potential carcinogens in the Drug Bank database. The results indicate that the proposed models are helpful in predicting the carcinogenicity of chemicals. A web server called CarcinoPred-EL has been built for these models. 


\section{International Journal of Advanced Research in Computer and Communication Engineering}

Vol. 8, Issue 5, May 2019

2. M. S. Mulyadi and Y. Anwar, "Corporate Governance, Earnings Management and Tax Management," Procedia - Soc. Behav. Sci., vol. 177, pp. 363-366, 2015.[1]

For the first time in Iran, this study aims at discussing the effect of corporate governance on employee voice. Reviewing basic theories of the research shows that corporate governance has a huge effect on employee voice. Therefore, in Iran insurance organization, the relation between corporate governance and employee voice outcomes has been analyzed. The result of this research denies the positive and meaningful relation between corporate governance with employee discouragement, organization indifference and inters organization objections and then confirms the positive and meaningful relation between corporate governance with increasing employee motivation and empowering them and their teamwork.

3. E. Rahimikia, S. Mohammadi, T. Rahmani, and M. Ghazanfari, "Detecting corporate tax evasion using a hybrid intelligent system: A case study of Iran,” Int. J. Account. Inf. Syst., vol. 25, pp. 1-17, 2017.[2]

This paper concentrates on the effectiveness of using a hybrid intelligent system that combines Multi Layer Perceptron (MLP) neural network, Support Vector Machine (SVM), and Logistic Regression (LR) classification models with Harmony Search (HS) optimization algorithm to detect corporate tax evasion for the Iranian National Tax Administration (INTA). In this research, the role of optimization algorithm is to search and find the optimal classification model parameters and financial variables combination. Our proposed system finds optimal structure of the classification model based on the characteristics of the imported dataset. This system has been tested on the data from the food and textile sectors using an iterative structure of 10-fold cross-validation involving 2451 and 2053 test set samples from the tax returns of a two-year period and 1118 and 906 samples as out-of-sample using the tax returns of the consequent year. The results from out-of-sample data show that MLP neural network in combination with HS optimization algorithm outperforms other combinations with $90.07 \%$ and $82.45 \%$ accuracy, $85.48 \%$ and $84.85 \%$ sensitivity, and $90.34 \%$ and $82.26 \%$ specificity, respectively in the food and textile sectors. In addition, there is also a difference between the selected models and obtained accuracies based on the test data and out-of-sample data in both sectors and selected financial variables of every sector.

\section{PROPOSED SYSTEM}

Following diagram is our system's architecture diagram:

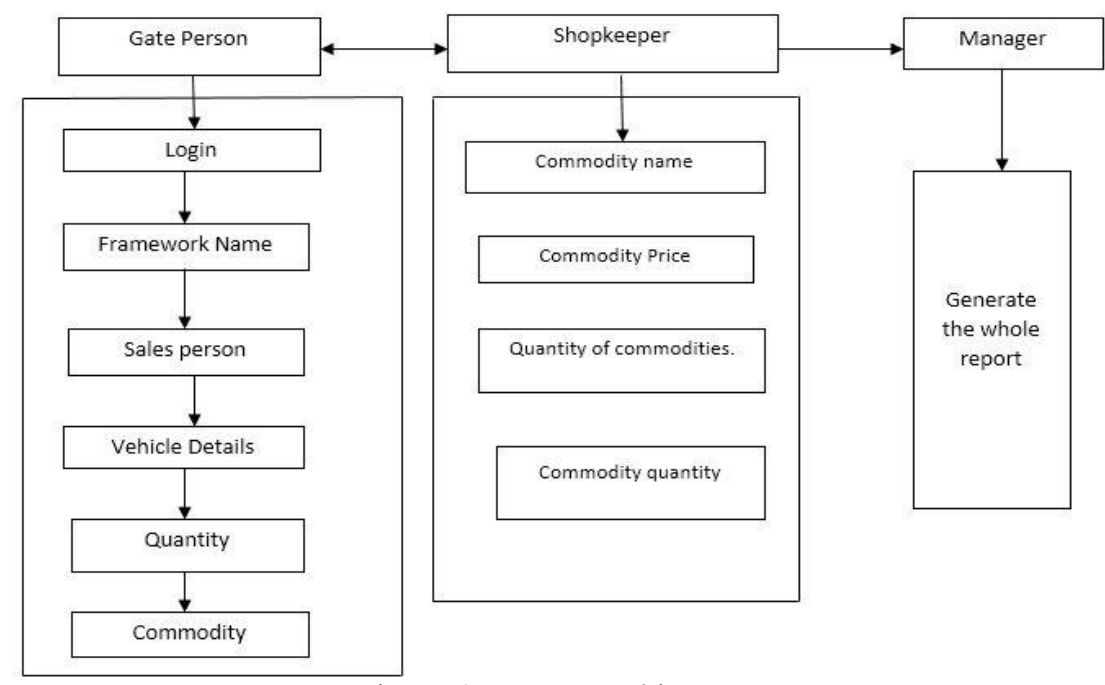

Figure 1: system architecture

In System architecture In system architecture market yard has a three main phases such as a following:

\section{Gate Entry}

In this phase the gate person can reusing application can register the application . then registration is successful then login the application. Gate person can check the following Scenario:-

1. Commodity type

2. Farmer name

3. Farmer City

4. Commodity Quantity

5. Vehicle number

6. Agent Name 


\section{International Journal of Advanced Research in Computer and Communication Engineering}

Vol. 8, Issue 5, May 2019

\section{Shopkeeper}

In this phase they can search the Commodity name and price. As well as the they can check the commodity quantity and Quantity of commodities.

3. Manager: - the whole report are generate to manager.

Data mining is crucial for extracting and identifying useful information from a large amount of data.

Kmean Algorithm-

The best number of clusters $\mathrm{k}$ leading to the greatest distance is not known as a priori and must be calculated from the data. The objective of K-Means clustering is to minimal total intra-cluster variance, or, the squared error function: Algorithm. Clusters the data into $\mathrm{k}$ number of groups where $\mathrm{k}$ is predefined.

Disicion Making

A subset of rules is selected from the many extracted knowledge to meet the established decision-making criteria. The parameter values presented by the conditions of this set of rules are called a decision signature. A model and algorithms for the selection of the desired, decision signatures will be developed. The parameters which is use in this model are upgrade using a framework provided by the learning classifier systems.

\section{MATHEMATICAL MODEL}

Mathematical Model:

$\mathrm{S}=\{\mathrm{s}, \mathrm{e}, \mathrm{i}, \mathrm{o}$, functions, DD, NDD, Success, Failure $\}$

$\mathrm{s}=$ initial state $=$ Registration and login

$\mathrm{e}=$ end state $=$ Manager view Report about all process

$\mathrm{i}=$ Input $=$ Using application farmer send this commodity to buyers

$\mathrm{o}=$ output $=$ Smart Market yard

Functions $=\{\mathrm{f} 1, \mathrm{f} 2, \mathrm{f3}, \mathrm{f} 4, \mathrm{f5}, \mathrm{f6}, \mathrm{f7}, \mathrm{f8}\}$

$\mathrm{f} 1=$ Registration

$\mathrm{f} 2=$ Login

$\mathrm{f} 3=$ Farmer

$\mathrm{f} 4=$ Agent

f5 $=$ Gateperson

f6 $=$ Commodity

$\mathrm{f} 7$ = buyers

Deterministic data $=$ for same input return the same result at any time

Non deterministic data $=$ result will vary every time for given input

success condition $=$ It will display the result

failure condition $=$ Wrong inputs.

\section{CONCLUSION}

To avoid the fraud like tax fraud and to track supplier and import- export vehicle. This system will manage by manager and they can see the Real time entries of Commodities. System will gives some authorities to the Shopkeeper in which they can edit following things How much Quantity sold out, Type of Commodities, Quantity of Commodities and also provide search option with filters like By Commodities, By Name, By Price.

\section{RESULT}

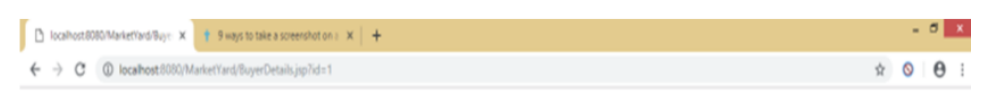

Daily Report

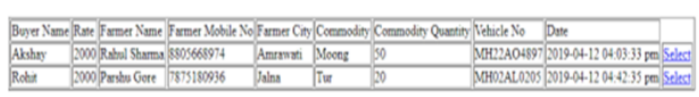


International Journal of Advanced Research in Computer and Communication Engineering

Vol. 8, Issue 5, May 2019

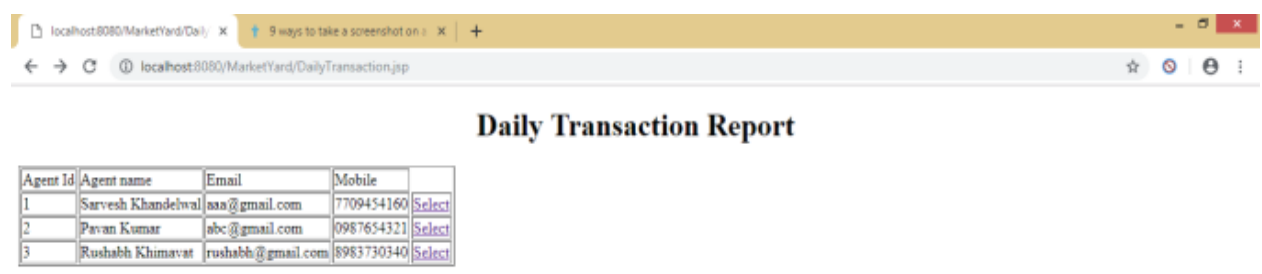

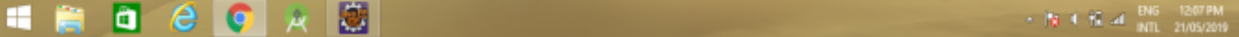

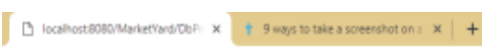

के $\odot \theta$

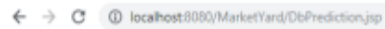

Prediction

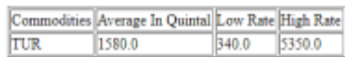

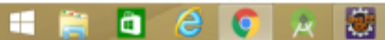

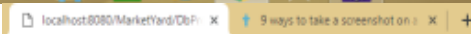

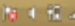

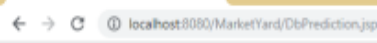

Prediction

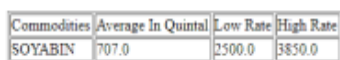




\section{International Journal of Advanced Research in Computer and Communication Engineering}

Vol. 8, Issue 5, May 2019

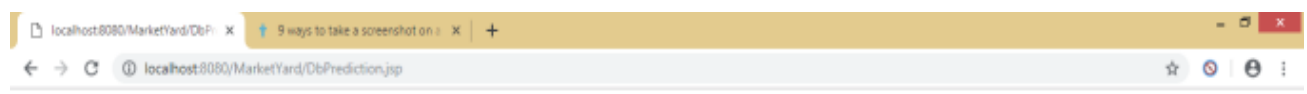

\section{Prediction}

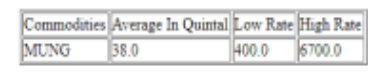

\section{GRAPH}

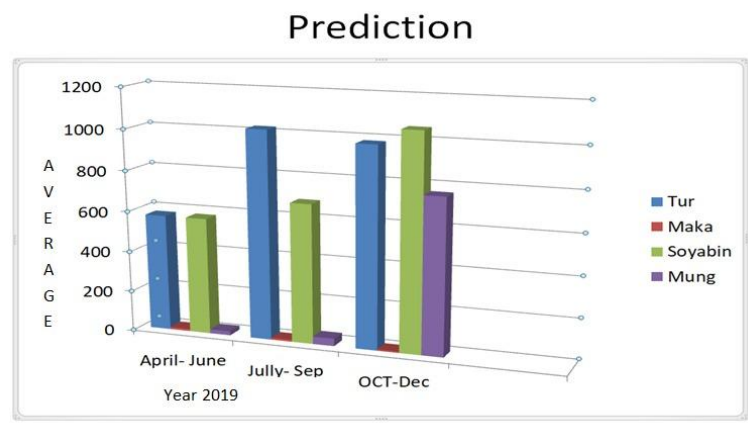

\section{REFERRENCES}

[1]. H. Witten, E. Frank, and M. a. Hall, Data Mining: Practical Machine Learning Tools and Techniques, Third Edition, vol. 54, no. 2. 2011.

[2]. M. K. A. J. P. Jiawei Han, "Data Mining: Concepts and Techniques, Third Edition - Books24x7," Morgan Kaufmann Publ., p. 745, 2012.

[3]. B. Y. Pratama and R. Sarno, "Personality classification based on Twitter text using Naïve Bayes, KNN and SVM," in Proceedings of 2015 International Conference on Data and Software Engineering, ICODSE 2015, 2016, pp. 170-174.

[4]. H. Zhang, Z. X. Cao, M. Li, Y. Z. Li, and C. Peng, "Novel naïve Bayes classification models for predicting the carcinogenicity of chemicals," Food Chem. Toxicol., vol. 97, pp. 141-149, 2016.

[5]. M. Mayilvaganan and D. Kalpanadevi, "Comparison of classification techniques for predicting the performance of students academic environment,” Commun. Netw. Technol. (ICCNT), 2014 Int. Conf. Comput. Intell. Comput. Res., pp. 113-118, 2014.

[6]. P.Suryachandra, "Comparison of Machine Learning Algorithms" 3rd Int. Conf. Sci. Technol. - Comp. Comp., vol.8, no.5, pp.2241-2247, 2017

[7]. A. M. Mubarek and E. Adali, "Multilayer perceptron neural network technique for fraud detection," 2017 Int. Conf. Comput. Sci. Eng., pp. 383-387, 2017. 